\title{
Exploring Teachers' Implementation of Comparison in Algebra I
}

\section{Citation}

Lynch, K. \& Star, J.R. (2014). Exploring teachers' implementation of comparison in Algebra I. Journal of Mathematical Behavior. 35, 144-163.

\section{Published Version}

doi:10.1016/j.jmathb.2014.07.003

\section{Permanent link}

http://nrs.harvard.edu/urn-3:HUL.InstRepos:12701474

\section{Terms of Use}

This article was downloaded from Harvard University's DASH repository, and is made available under the terms and conditions applicable to Open Access Policy Articles, as set forth at http:// nrs.harvard.edu/urn-3:HUL.InstRepos:dash.current.terms-of-use\#OAP

\section{Share Your Story}

The Harvard community has made this article openly available.

Please share how this access benefits you. Submit a story.

Accessibility 


\title{
Running head: TEACHERS’ IMPLEMENTATION OF COMPARISON CURRICULA
}

\section{Exploring Teachers’ Implementation of Comparison in Algebra I}

\author{
Kathleen Lynch and Jon R. Star
}

Harvard University

June 17, 2014

Kathleen Lynch and Jon R. Star, Graduate School of Education, Harvard University.

Acknowledgements: Thanks to Courtney Pollack, Nataliia Perova, Kristie Newton, Bethany Rittle-Johnson, and Erin O'Connell for their assistance in data collection and analysis. This research is supported by a grant to the second author from the National Science Foundation (DRL0814571).

Correspondence should be addressed to Jon R. Star, 442 Gutman Library, 6 Appian Way, Harvard Graduate School of Education, Cambridge, MA, 02138; 617-496-2511 (voice), 617496-3095 (fax), jon_star@harvard.edu. 


\begin{abstract}
Discussions where teachers engage students in the comparison of multiple solution strategies to a single problem have been recommended in curriculum policy documents, yet integrating these discussions into teachers' normative routines is not widespread. In this paper, we begin to explore variations in teachers' implementation of Algebra I curriculum materials specifically focused on comparison. We explore (via case studies) implementation of the curriculum materials by two teachers with similar teaching backgrounds. The case studies suggest that these two teachers' implementation of the comparison materials differed markedly, raising questions about possible factors which may have contributed to implementation differences.
\end{abstract}

Keywords: Comparison, instructional practices, curriculum implementation 


\section{Exploring Teachers’ Implementation of Comparison in Algebra I}

Mathematics curriculum policy documents in the United States argue that students should be provided with opportunities to compare and discuss multiple strategies for solving mathematics problems. For example, a recent Institute of Education Sciences practice guide focused on improving students' skills in mathematical problem solving recommends that "teachers instruct students in a variety of strategies for solving problems and provide opportunities for students to use, share, and compare the strategies” (Woodward et al., 2012, p. 32). Early research projects conducted with students in the primary grades, such as the Cognitively Guided Instruction (CGI) project, illuminated the benefits that young children can derive from comparing and discussing multiple problem solving strategies with their peers (e.g. Fennema, Carpenter, Franke, Levi, Jacobs, \& Empson, 1996). More recently, the Common Core State Standards for Mathematical Practice state that students should be able to "understand the approaches of others to solving complex problems and identify correspondences between different approaches” (National Governors Association Center for Best Practices, 2010).

However, despite policy reports and research suggesting the potential learning benefits of instruction incorporating the comparison of multiple strategies, there has been relatively little research into how the comparison of multiple solution strategies may be implemented at the introductory algebra level. Developing effective instructional strategies for Algebra I is an important policy concern, because algebra is widely considered a key "gatekeeper" subject associated with admission to advanced educational and career pathways (Moses \& Cobb, 2001; Stein, Kaufman, Sherman, \& Hillen, 2011). 
One Algebra I instructional strategy which appears promising based on early studies is guiding students to compare and contrast two 'contrasting cases,' or worked examples which depict algebra problems solved using multiple strategies presented side-by-side. We note before proceeding that this approach differs from that explored in other research projects, such as CGI, which emphasized students' invention of their own strategies. The current intervention does not focus on students inventing their own strategies for Algebra I problems, but instead emphasizes students' comparison and discussion of pairs of already-worked examples. The current approach differs from that used in prior studies conducted at the elementary level, yet shares the goal of supporting students' conceptual and procedural learning, through participation in a structured discussion focused on specific learning goals for each comparison pair. We return to this issue below.

Results from several relatively short-duration research experiments suggest that comparing worked examples that depict multiple solution strategies side-by-side may help early algebra learners to develop their procedural flexibility, or their ability to solve problems using different strategies and to adaptively select strategies appropriate to the problem posed (Woodward et al., 2012). The National Research Council’s report Adding It Up highlighted the importance of flexibility as a tool for problem-solving, describing flexibility broadly as “a fundamental characteristic needed throughout the problem-solving process” (Kilpatrick, Swafford, \& Findell, 2001, p. 126). Procedural flexibility may be the most proximal outcome to comparison interventions (Woodward et al., 2012). For example, in two short-term randomized experiments on algebraic equation-solving, Rittle-Johnson and Star found that seventh- and eighth-grade students who were prompted to examine pairs of worked examples that presented multiple solution strategies to the same problem side-by-side, and to compare these two 
strategies, performed better on posttest measures of procedural flexibility than their peers who were prompted to examine the same strategies presented one after the other (Rittle-Johnson \& Star, 2007), or to examine sets of similar problems solved using one strategy (Rittle-Johnson \& Star, 2009). In a third study the researchers found that the effectiveness of this approach may have been sensitive to students' prior knowledge, with students who demonstrated some prior knowledge of algebra at pretest experiencing greater learning gains from comparing multiple strategies than those demonstrating no prior knowledge (Rittle-Johnson, Star, \& Durkin, 2009). However, each of these interventions was relatively short, lasting only several class periods. In addition, the effects on overall conceptual and procedural outcomes varied across studies, possibly due to variability in the content presented in the short-term interventions.

One possible challenge inherent in implementing the Common Core State Standards is that the Standards call for teachers to implement instructional practices which are unfamiliar to many Algebra I teachers, such as engaging students in mathematical discussions where they compare and contrast multiple solution strategies for solving algebra problems (Silver et al., 2005). Prior work has found that integrating discussions where teachers engage students in the comparison of multiple solution strategies to a single problem into teachers' normative routines is not widespread (e.g., Hiebert, Gallimore, Garnier, Givven, Hollingworth, Jacobs, et al., 2003). To date, there has been relatively little exploration of how curricula emphasizing the comparison of multiple strategies (a practice recommended by the NRC and the Common Core) might be implemented in regular classroom settings with the full content of the Algebra I course.

This suggested the need for the current exploratory pilot research, to investigate how learning with comparison might be implemented outside the lab, in regular Algebra I classroom settings. In the current paper, then, we extend this work by looking at variations in middle school 
teachers' implementation of an Algebra I curriculum specifically focused on comparison. We explore (via case studies) two teachers whose demographic profiles and years of teaching experience were quite similar, but whose implementation of comparison was very different. Our findings raise questions about the possible roles that factors such as mathematical knowledge for teaching and beliefs about the value and goals of engaging students in comparison may have played in shaping implementation of the comparison curriculum.

In the project from which the current data are derived, we conducted an exploratory pilot study to examine teachers' use of a set of new, researcher-developed curriculum materials designed to 'infuse' the comparison of multiple solution strategies into teachers' regular, yearlong Algebra I courses. As we describe in further detail below, the curriculum materials featured two cartoon characters named Alex and Morgan, who solved algebra problems using multiple strategies. As we also discuss below, the curriculum materials prompted teachers to engage students in a three-phased discussion, with question prompts in each phase designed to encourage students to (1) understand, (2) compare, and (3) make connections among the compared strategies.

\section{Challenges to implementing reform instructional practices}

Prior studies have documented myriad challenges that teachers may experience when asked to implement new instructional reforms, ranging from misalignment between teachers' attitudes and beliefs and the goals and practices envisioned in the reform (e.g. Borko, Mayfield, Marion, Flexer, \& Cumbo, 1997), to limitations on resources such as curriculum materials and professional learning opportunities aligned with the new reform (e.g. Coburn, 2005; Cohen \& Hill, 2000; Cohen \& Hill, 2001). Regarding attitudes, for example, prior research has found that even some middle grades teachers who were experienced and supportive implementers of a 
reform-oriented, NSF-funded mathematics curriculum expressed some doubts about the benefits of teaching with multiple strategies, and apparent reluctance to expose students to multiple strategies for unfamiliar material (Silver et al., 2005). More broadly, scholars have found that teachers' implementation of new curricula is shaped by a complex web of factors including attitudes, beliefs, prior experiences as learners and teachers, perceptions of their students, school climate, training and professional development experiences, mathematical content knowledge, and pedagogical content knowledge (e.g. Coburn, 2005; Cohen \& Hill, 2001; Philipp, 2007).

Of the many factors which contribute to teachers' implementation of challenging new pedagogical practices, one factor which some scholars have highlighted as particularly influential is teachers’ mathematical knowledge for teaching, or MKT. Hill, Blunk, Charalambous, Lewis, Phelps, Sleep, \& Ball (2008) define mathematical knowledge for teaching as "not only the mathematical knowledge common to individuals working on diverse professions, but also the subject matter knowledge that supports that teaching, for example, why and how specific mathematical procedures work, how best to define a mathematical term for a particular grade level, and the types of errors students are likely to make with particular content” (p. 431). The MKT research may be situated in a long history of research documenting ways in which a teacher's strong mathematical knowledge may enrich a lesson, as well as ways in which weak points in a teacher's mathematical understanding may limit a lesson's effectiveness (e.g., Fennema \& Franke, 1992; Lampert, 2001; Lloyd \& Wilson, 1998; Putnam, Heaton, Prawat, \& Remillard, 1992; Stein et al., 1990).

Building on this work, Hill, Rowan, and Ball (2005) sought to estimate the quantitative impact of teachers' mathematical knowledge for teaching on students' mathematics achievement gains. They developed the Mathematical Knowledge for Teaching (MKT) teacher assessment to 
capture both teachers' 'common' or general mathematical knowledge (such as the fact that $8^{0}=1$ ) as well as specialized knowledge for teaching (such as interpreting students' multiple solution strategies and discerning appropriate from inappropriate teacher explanations for mathematical concepts). See Figures 1 and 2 for examples of released items from earlier administrations of the MKT assessment.

Prior research has demonstrated that MKT is an important predictor of teachers' implementation of curriculum materials (Hill et al., 2008). In prior studies, researchers have measured teachers' MKT using paper-and-pencil assessments, with separate forms for elementary and middle school teachers. Prior studies have found that the MKT assessments meet widely accepted standards for reliability and validity. For example, internal consistency reliability (alpha) estimates of MKT forms are reported in the range of .8 and above (Hill, Schilling, \& Ball, 2004). Evidence from retrospective think-aloud interviews suggested that MKT test-takers' thinking processes were consistent with their responses to test items (Hill, Dean, \& Goffney, 2007). In addition, evidence for the validity of the MKT assessments is drawn from studies indicating that on average, teachers with higher MKT scores received higher scores on a classroom observation metric evaluating the mathematical quality of their instruction (Hill, Ball, Blunk, Goffney, \& Rowan, 2007); and on average, students whose teachers had higher MKT scores demonstrated larger student achievement gains (Hill, Rowan, \& Ball, 2005). Specifically, in a study of school improvement, Hill and colleagues found that over one school year, students whose teachers scored one standard deviation higher on the MKT assessment had student achievement gain scores on standardized Terra Nova exams that were approximately .1 standard deviations higher than their counterparts whose teachers had lower MKT scores (Hill, Rowan, \& Ball, 2005). 
Prior to beginning, then, we hypothesized that implementing the new, comparisonfocused supplemental algebra curriculum materials could introduce new learning opportunities, but also complexities and challenges for teachers. A goal of the case studies we explore in the current paper was to raise questions about possible implementation variations and challenges that Algebra I teachers might encounter in teaching with comparison, to inform subsequent research and inquiry in this area.

\section{Method}

In this section, we provide a brief description of the professional development and curriculum that provided the context for this study. We then describe the types of data collected and the process by which the data were analyzed.

\subsection{Setting}

We collected data for the current study during the pilot year of a multi-year study aimed at examining instruction incorporating the comparison of multiple strategies in Algebra I classrooms. In the summer prior to the pilot study year, 12 middle and high school Algebra I teachers participated in a week-long professional development institute that was facilitated by the second author. The goal of the institute was to introduce and build teachers' familiarity with a set of new, researcher-developed supplemental curriculum materials which emphasized the comparison of multiple strategies for solving Algebra I problems presented side-by-side. The MKT algebra instrument was administered to all teachers in the first day of the professional development week. During the subsequent academic year, teachers were asked to implement the new materials in their Algebra I courses at least once per week. 


\subsection{Participants}

Twelve teachers participated in the professional development institute and curriculum materials piloting during the pilot year of the study. These teachers taught at a mix of urban and suburban schools serving students from a range of backgrounds and had an average of ten years of experience. The teachers were recruited through a mix of print and email advertisements seeking experienced Algebra I teachers (which we defined as those not in their first year of teaching) who wished to explore new algebra teaching methods. Teachers were paid an honorarium for their participation in the project.

The two teachers for whom we present case studies in the current study were the highestand lowest-scoring teachers on the MKT algebra instrument, Anna and Valerie (all names are pseudonyms). Apart from their differences on the MKT, these two teachers were quite similar on many characteristics. Anna and Valerie were both in their forties, and each had the same number of years of teaching experience (fewer than five). Both had master's degrees as well as similar previous professional backgrounds. Each taught eighth-grade Algebra I, although their schools and student populations were somewhat different. Anna taught in a diverse, urban school that served many students from low-income families, and students of all abilities were grouped together to complete Algebra I in the eighth grade. Valerie taught honors eighth grade Algebra I in a predominantly middle-class suburb. Indeed, Valerie's students scored about 20 percentage points higher than Anna's, on average, on a standardized algebra readiness pretest at the beginning of the project year. Both Anna and Valerie were identified by their colleagues as leaders in their departments and in their schools. Both attended in its entirety the same summer professional development institute that focused on helping teachers learn about and prepare to 
implement curriculum materials infusing comparison into their Algebra I courses during the following academic year.

While they shared many similarities in their backgrounds, Anna and Valerie differed substantially in their scores on the MKT instrument that was administered on the first day of the summer professional development institute. On this instrument, Valerie scored in the $37^{\text {th }}$ percentile as compared with a larger norming sample of teachers, whereas Anna scored at the $97^{\text {th }}$ percentile. Note that while Valerie received the lowest score among the teachers in our pilot sample, her score was only in about the bottom third compared to the larger sample of teachers with whom the MKT instrument was previously piloted (Hill, Rowan, \& Ball, 2005). Anna's score, the highest in our pilot sample, was very high compared to this larger sample. Note that one challenge in presenting our analysis is that the MKT is a secure instrument. As a result, we cannot provide specific items from the MKT to illustrate the types of items that each teacher answered correctly or incorrectly. Instead, we can only report generally on the MKT assessment results.

\subsection{Comparison Curriculum Materials}

The comparison curriculum materials were developed by a team of university-based researchers (including the authors) in collaboration with a panel of experienced mathematics teachers from local secondary schools. The materials feature the characters Alex and Morgan, who solve problems in two different ways (see Figure 3). We provided participating teachers with approximately 80 lessons featuring Alex and Morgan covering a broad range of Algebra I content. Teachers could choose which curriculum materials to use on any given day, with the guideline that the comparison curriculum materials would be used approximately once per week for the entire yearlong Algebra I course. 
The curriculum materials included an emphasis on engaging students in what we termed “comparison conversations,” in which teachers and students were asked to engage in a discussion aimed at understanding Alex's and Morgan’s solution strategies for each problem, comparing and contrasting Alex's and Morgan's strategies, and drawing conclusions and articulating generalizations based on the comparison. In particular, the curriculum materials asked teachers to guide students through three critical "discussion phases": (1) in the Understand phase, students and teachers were asked to answer questions aimed at developing students' understanding of how Alex and Morgan had each solved the problem; (2) in the Compare phase, students and teachers were asked to discuss the similarities and differences between Alex's and Morgan's approaches; and (3) in the Make Connections phase, students and teachers were asked to draw conclusions about what they had learned from comparing Alex's and Morgan's approaches, to probe why and in what contexts diverse strategies might be more efficient or less error-prone than others, and to articulate broader conclusions and mathematical generalizations that could be gleaned from the comparison.

Each Alex and Morgan lesson was classified into one of four categories, depending on the key mathematical goal of the lesson. These categories included (1) Which is better?, which focused on exploring why and under what conditions one method might be better than another for solving particular problems; (2) Which is correct?, which focused on exploring why a given method was correct and a common error was incorrect; (3) How do they differ?, which focused on the relationships between different problems, and what these relationships could demonstrate about the underlying concepts; and (4) Why does it work?, which focused on uncovering and understanding the conceptual rationale behind a method. For a detailed discussion of each of these comparison types and the supporting research base, see Rittle-Johnson \& Star, 2011. 
During the professional development institute, teachers were provided with training and practice in leading discussions that progressed through these three discussion phases. For example, teachers observed a teaching demonstration led by the second author, engaged in small and large group discussions of the comparison curriculum's worked example pairs, and participated in model teaching activities in which they practiced with their peers teaching and leading comparison-oriented classroom lessons. For each comparison lesson, teachers were provided with a set of discussion questions, as well as sample answers. For more details on the pilot year professional development institute, see Newton and Star (2013). We note that given the exploratory nature of the current pilot study, the professional development institute emphasized that teachers would have considerable latitude in their implementation of the curriculum materials during the pilot year. As we discuss further in the Discussion section, our observations of the variations in teachers' implementation of the comparison materials during the pilot year informed our later refinement of our professional development activities, in order to highlight for teachers more clearly the intended structure and architecture of the three discussion phases.

\subsection{Data Sources}

Data analyzed in the current study included teachers' scores on the MKT assessment prior to the project year, as well as video recordings of teachers' lessons collected over the course of the year. We describe each of these data sources below.

At the start of the study, as the first activity conducted on the first day of the summer professional development institute, all teachers completed the algebra items of a paper-andpencil assessment of their MKT (Hill, Rowan, \& Ball, 2005). Subsequently, throughout the following academic year we videotaped each teacher's class approximately once per month 
during a class period in which the teacher used our researcher-developed curriculum materials. Each teacher's class was videotaped approximately ten to twelve times over the course of the year, and each lesson was videotaped in its entirety by trained research assistants on the project. The videotaped lessons were approximately 45-60 minutes in duration. We analyzed twelve videotaped lessons from Anna's class and ten videotaped lessons from Valerie's class. For the current study, we focused our analysis on the portions of the lessons in which teachers utilized the comparison materials; the duration of these segments typically ranged from approximately 15 to 30 minutes.

\subsection{Analysis}

Analysis was conducted collaboratively by both authors and by an additional trained research assistant on the project. The MKT assessment was hand-scored by a trained research assistant, using the multiple-choice answer key provided by the test developers. To explore classroom implementation, both authors first viewed a sample of videos from all of the teachers in the study as a whole in order to become acquainted with the range of implementation strategies that teachers employed in the course of teaching with the curriculum materials over the course of the year. For the two teachers whose classes we analyze below in the case studies, we then watched all of the class segments in which the teachers used the comparison materials, read the transcripts, and met multiple times to discuss and challenge emerging themes in the data. We viewed each case holistically, and we attempted to parse the many levels of the variations in teachers' implementation.

\section{Results}

In order to explore variability in implementation of the comparison curriculum materials as illustrated in the two case study teachers, we sought to answer the question: What differences 
existed between the two case study teachers' implementation of the comparison curriculum? We explored this questions in the context of the cases of Anna and Valerie. Below we present our analysis of the first question (differences in Anna's and Valerie's implementation of the curriculum); we subsequently explore the second question (possible factors contributing to these differences in implementation) in the Discussion section.

Before beginning, it is worth noting that at the beginning of the study, all of the teachers in the study were already familiar with the idea of teaching with multiple strategies. In interviews conducted on the morning of the first day of the professional development institute that preceded the pilot study year, all of the teachers in the pilot sample (including Anna and Valerie) reported that they were familiar with the notion of teaching with multiple strategies, and indeed that they already incorporated multiple strategies in their teaching. This was not surprising, considering that the pilot study sample was comprised of teachers who volunteered to participate in a summer institute and yearlong pilot focused on multiple strategies in Algebra I. We indeed hypothesized that the teachers in the current study were likely above average in their support and enthusiasm for teaching with multiple strategies compared with the general teacher population. However, as is reported elsewhere (Lynch \& Star, in press), beneath their shared endorsement of the idea of teaching with "multiple strategies," at the beginning of our study teachers varied widely in their conceptions of what “multiple strategies” were, their beliefs about why teaching with multiple strategies was important, and their concerns about the potential risks of presenting multiple strategies to students. In addition, prior to beginning the study, teachers generally reported that they had limited experience incorporating comparison into their instruction.

In response to our research question about differences in Anna's and Valerie's implementation of the comparison curriculum, we identified three levels on which 
implementation differences were observed: (1) mathematical issues; (2) general pedagogical issues, and (3) structural issues of lesson organization.

\subsection{Mathematical Issues}

In that the comparison curriculum was designed around facilitating mathematically rich discussions, the two teachers appeared to differ in the manner in which they responded to students' mathematical contributions. In particular, the two teachers differed in the ways in which they responded to students' mathematical errors and responded to students' suggested alternative methods. A second difference was in the ways in which the two teachers cast the focus of the "Make Connections" discussion phase. While Anna typically framed the goals of comparison as primarily mathematical, Valerie at times framed the goals of the comparison in terms of identifying personal preferences. We discuss these two differences below.

\subsubsection{Responses to errors and alternative methods}

First, Anna and Valerie differed in their responses to students' errors and alternative methods as they arose in class. During the comparison discussions in Valerie's class, Valerie at times appeared to miss opportunities to address students’ questions, concerns, and suggestions for possible solution strategies. Valerie's pattern in responding to students' mathematical contributions is illustrated in the following example, from a lesson using the curriculum materials depicted in Figure 4:

Valerie: We're going to start the review... Okay, I want to start the review with this equation. I want you guys to evaluate, and find the value for $x$. Okay remember, this is an equation, right? So you should be able to use the properties of equality to solve it, or use the rules of evaluating an equation. Okay, you should be able to answer that. I'm seeing a lot of negative two's. There is a solution to this. This is an equation, just 'cause this is an 
equation involving a fraction doesn't mean you don't know how to do it. You still have to follow the same rules. So whatever you do to the left side of the equation, you have to do to the right side of the equation. [one minute passes] And you can't just multiply one term by something, and not multiply the other term by the same value. All right, I know two people have the correct answer. Does anybody else have an answer they'd like to? [Student raises hand; Valerie walks over and looks at student's paper.] Valerie: Did you plug that back in? [Another student raises hand; Valerie walks over and looks at student's paper.] Valerie: Three. Those of you who have it, you know it's right. All right. Now you know you all have the ability to do this problem. Now let's take a look. I'll show you the answer in a minute. [opens worked example pair slide on the Smartboard] The answer, um, Ben was...

Ben: Negative forty?

Valerie: Negative forty. $x$ equals negative 40. So let's take a look at what's happening. Student: I was thinking about that, but I didn't think it was right, so I just didn’t do it. Valerie: You were thinking about what?

Student: Um, the five?

Student: I got twenty first, and then I got negative one, and then [inaudible] Valerie: Wait. I can only listen to one person at a time. So Steven? Steven: Um, five times, like, never mind.

Valerie: So how many people were thinking, I have two fractions, I need a common denominator [raises hand]. Raise your hand everybody who was thinking that. All right, so that's what you were thinking. So when you got the idea of a common denominator, 
what were you doing to try to get a common denominator? What did you find was your lowest common denominator? Were you all saying twenty? So what were you doing to get to your common denominator?

Student: Multiplying the two denominators and the two numerators by the same? So multiplying four times five and $x$ times five?

Valerie: If I were changing this to a common denominator of 20 I'd multiply both of these by five [pointing to $\frac{x}{4}$ in the original problem] and both of these by four. Is that what you said you did?

Student: Uh-huh.

Valerie: So what did you get? So you should have had $5 x$ over 20 times $4 x$ over 20? Did you get this expression? [points to Morgan's second step]

Student: No, I got the wrong answer.

Valerie: Okay. So if you did not get the answer, I want you to write these down.

At the beginning of this segment, all but three students in the class appeared to be struggling to solve the problem that was the focus of the comparison lesson. Several students attempted to describe their thinking about the problem, but Valerie appeared to give up on probing their ideas before she had interpreted their mathematical errors.

While it may have been impractical for Valerie to probe every student response and error, it did appear that inadequate attention to students' questions and comments during the “Understand” phase may have hampered Valerie’s ability to move the mathematics of the comparison activity along in the subsequent phases. Perhaps related to issue that the “Understand” phase was inadequately addressed (e.g., students did not understand how Alex solved the problem and how Morgan solved the problem), Valerie was frequently interrupted by 
students with comprehension questions while she attempted to move on to the next phases in the discussion sequence. For example, at the conclusion of the above lesson, students still expressed confusion in comprehending how the two methods that were the focus of the comparison worked, as in the following exchange:

Valerie: All right, so are you guys good to do this?

Students: No! No!

Valerie: No? [laughs] ... This you should be able to do. You don't need me to do this part.

Student: I got it wrong, but I don’t know if it was...

Student: Minus 2x gets 13.

[Valerie finishes problem on board]

Student: Is this on our homework?

Valerie [finishes writing]: $x$ equals 12.

Student: Is this on our homework?

Valerie: Why?

Student: Are there problems like this on our homework?

Valerie: Why does that matter? I'm curious.

Student: I struggle.

Student: Yeah, every problem takes like 5 minutes.

Valerie: What?

Student: Every problem takes 5 minutes. 
Valerie: Every problem takes 5 minutes. How many people at least got to here? [Valerie points to intermediary step] Aren't these the same things that we have been doing all this time, it’s just that we haven’t necessarily been doing them with a fraction.

Student: Wait, I have a question.

Valerie: Aren't they all opposite operations?

James: The fractions make it harder.

Valerie: How do they make it harder?

James: I don’t know, it just does.

Valerie: I don’t know you guys, I’m getting worried.

Bill: You have to show your work.

James: Well I did.

Valerie: Maybe, exactly. Thank you Bill!

James: Well I did this time, and it didn’t work, so.

Valerie: And that's exactly what I'm talking about, James. When you don't show your work consistently, when the problems get too hard to do in your head, you have not had enough practice of showing your work and going through all the steps [gestures to indicate steps going down] to be able to do it out accurately, and that's where you're having this problem. That's just a fact. Yeah, we're going on. All right. Chapter review.

In this segment, Valerie appears to discount a student's assertion that introducing fractions to the mix in solving linear equations adds complexity to solving for a variable in these equations. Indeed, Valerie asserts that students should be able to solve problems of the type they are considering because these problems merely involve applying principles of equality, such as remembering that if one adds a value to one side of the equation, one must add the same value to 
the opposite side of the equation. These characterizations actually may over-simplify the mathematical complexity that introducing fractions to these problems can add, besides neglecting the intended mathematical goal of the comparison problem, which was to analyze the relative ease and efficiency of each of the methods presented. Furthermore, Valerie concludes the lesson by suggesting that students' difficulties in understanding the various methods that were presented may have to do not with some feature of the mathematics under consideration, as a student proposed, but rather to students’ failure to clearly and systematically record their steps in writing. By contrast, Anna’s typical response to students’ mathematical contributions was quite different. For example, in responding to students' errors, Anna’s typical response was to ask the class what they thought about the erroneous statement, as in the following example from the lesson described above (see Figure 5):

Anna: Okay, let's talk about these. The first question on the back is, "How did Alex simplify the expression?” So using your own words, what did Alex do? Carlos, what did Alex do?

Carlos: He used the product of powers property, added the exponents and got three to the seventh.

Anna: Okay. What do you guys think about Carlos’s description there?

Andrew: Well, he had the wrong person.

Anna: Hmm.

Student: He said Morgan’s! It should be Alex’s!

Student: It's the one on the left!

Student: Morgan’s right.

Carlos: Oh, whoops! Okay. 
Anna: Okay. Carlos just did a fine job of explaining how Morgan did it. Jasmine, can you tell us how Alex did it?

Jasmine: He multiplied the exponents together, and he got three to the twelfth.

Anna: Okay. He got three to the twelfth. Okay.

In this example, when Carlos described Morgan's solution strategy in response to a question about Alex’s strategy, Anna asked the class what they thought about Carlos's statement. Other students in the class quickly spoke up and corrected the erroneous statement. Anna then recapped the correct answer.

In addition to responding to student errors by presenting them to the class for consideration, Anna responded to students' own suggested mathematical ideas by presenting them to the class for consideration and asked questions to scaffold students' thinking about their proposed methods. Indeed, Anna appeared adept at interpreting students' own suggested problems and methods. It appeared to be a norm of the class that students proposed their own alternative scenarios, which they called "what if" problems, and that Anna interpreted and wrote them on the board almost immediately as students described them. For example, in the middle of one comparison discussion (see Figure 6 for the example students were discussing), Anna responded to a student who suggested an alternative problem as follows:

Evan: What if we did ten to the $8^{\text {th }}$ power-

Anna: Yes- [writes $10^{8}$ on Smartboard]

Evan: And ten to the $7^{\text {th }}$ power.

Anna: Do you mean that 10 to the $7^{\text {th }}$ power will be in your denominator?

Evan: Mm-hm. 
Anna: Yeah? Okay. [writes $/ 10^{7}$ ] So Evan is asking us about this. He gave us a "what if" problem. Do you want to talk about it, Evan?

Evan: Sure. 10, it would be, 10-1, 10-2, 10-3 - It would be 10 to the 8 power minus 7.

Anna: Beautiful. [writes 108-7] And that gives us?

Evan: 10 to the 1.

Anna: [writes $=10^{1}$ ] What's another way to write 10 to the 1 ?

Evan: Ten!

Anna: [writes =10] Okay. Everyone okay with Evan’s example?

Students: Yes.

In this example, when Evan suggested an alternative problem, Anna wrote it on the board to present it to the class for consideration. She invited Evan to talk about it, and asked him questions as he talked to scaffold his thinking about the method he was using. She affirmed the correct answer once it was reached, and checked briefly with the class for their understanding of Evan's example.

\subsubsection{Implementation of the "Make Connections" phase}

In addition to the above-noted differences in how Valerie and Anna responded to students' mathematical errors and alternative methods, a second difference in the mathematical character of teachers' enactment of the comparison curriculum occurred during the phase of the worked example pair discussion that we called the "Make Connections" phase. The "Make Connections" phase is what we consider to be the most critical phase of the comparison conversations that teachers facilitate during the comparison curriculum. The goal of this phase is for teachers and students to discuss the mathematical crux of each comparison pair, parsing, for example, why the various strategies being compared work, when and why some strategies are 
more advantageous than others, why a given strategy is or is not mathematically correct, how multiple problems differ mathematically, and whether and to what extent a given strategy is generalizable to other contexts.

Anna and Valerie differed markedly in their enactment of the "Make Connections" phase. During this phase, Anna frequently asked students to justify their conclusions to the questions posed in our curriculum using more abstract terms. By contrast, Valerie sometimes conducted votes or polls of students' preferences for one strategy or another during this phase. This practice appears to have had the potential to obfuscate the mathematical nature of the goals of the comparison lesson. This practice seems concerning because it seems possible that taking a vote on which method students prefer could imply to students that the goal of the comparison activity is to find one's personal favorite methods, rather than to probe the various methods' mathematical differences and merits.

Anna's emphasis on pushing students for justification of their responses during the “Make Connections” phase characterized her teaching across lessons. She repeatedly probed students with questions such as, “How do you know?”, “Do you know how to tell for sure?”, “Why do you think she did that?”, “How would you convince somebody?” and "If I disagreed with you and I said that's the right answer, how would you prove to me that hers is right?” She displayed prompts on the Smartboard that scaffolded students' development of their justifications, such as "Maybe: Use an example” and “Maybe: Substitute values for $x$." The following instance was typical of Anna's instruction in the "Make Connections" phase (see Figure 5):

Anna: Which answer is correct? Is it Alex, or Morgan's? And the most important part of this is, how do you know? How do you know? Do you want to start 
us off, Jordan?

Jordan: Well, first I looked at [Alex's answer] and I said it was really big.

Anna: And you said it's monstrous.

Jordan: Yeah.

Anna: Okay. Go ahead.

Jordan: Then I looked at Morgan's and I seen, three to the second power times three to the third power times three to the second power. And then I did nine times twenty-seven times nine, and I got her answer.

Anna: You got her answer. Do you guys hear what Jordan did there?

Student: No.

Anna: You didn't? What Jordan said was, he said, look, you know, three squared is nine [writes 9 above $3^{2}$ ]. And he said three to the third power is 27 [writes $* 27$ above $3^{3}$ ). Right Jordan? ... And he doesn't get this monstrous thing, he gets what Morgan got there. Yes, Chris?

Chris: And another way I did it was uh, three squared is three times three--

Anna: Yes - [writes $3 * 3$ under $\left.3^{2}\right]$

Chris: Three cubed is three times three times three -

Anna: Good - [writes $3 * 3 * 3$ under $\left.3^{3}\right]$

Chris: And three squared is 3 times 3, and I mean, that made more sense to me than Alex’s way.

Anna: [writes $3 * 3$ under $3^{2}$ ] Okay good, so this way you count up your three's, 1, 2, 3, 4, 5, 6, 7, and get 3 to the seventh. And that's another way that Chris verified this three to the seventh here. 
In this segment of the "Make Connections phase," Anna appears to interpret students' mathematical ideas quickly as she displays them on the board for the class to consider. She opens the discussion by emphasizing that students will need to justify their responses, telling students that explaining "how [they] know" which solution strategy is correct is "the most important part of this.” Further, Anna accepted multiple student justification strategies, displaying several students’ evidence to support their answers for the class’s consideration.

While Anna's enactment of the "Make Connections" phase consistently centered on mathematical justification, Valerie's enactment of this phase at times emphasized students' personal preferences among the methods. For example, in a lesson where students were asked to compare multiple methods for determining whether a relation was a function, including using a table of values or using the vertical line test (see Figure 7), Valerie polled students on what they perceived to be their learning styles:

Valerie: Okay. So yeah, that one's pretty straightforward. Alex is using an input-output table. This is more of looking at the relation in table form versus in graphed form. Which would you say is, maybe. How many people consider themselves, like, a visual learner? Like you usually draw diagrams and stuff?

[Several students raise hands]

Valerie: All right so if your hand is up, how many of you, of those with your hands up, like Morgan’s way better?

[Some students raise hands.]

Valerie: Okay. So it's more like a visual sort of a method for looking at, for analyzing the data. 
In this lesson, Valerie did go on to attempt to compare the methods at greater length; however, conducting a poll of students' learning styles does seem to send a potentially mixed message to students about the goal of the comparison. Here, the reason Valerie proposes for why students might prefer one method over another is non-mathematical. By emphasizing the idea that different students might prefer different methods as a result of their individual learning styles, conducting a learning styles poll may de-emphasize the mathematical nature of the comparison activity, obscuring the goal of considering the mathematical relationship among the methods.

\subsection{General Pedagogical Issues}

The comparison curriculum, the new curriculum that teachers were attempting to implement, has an important focus on posing questions and having students answer the questions, often in the form of a discussion. We found that Valerie and Anna differed markedly in the general manner in which they managed classroom discussions, and thus in the manner in which they enacted this important component of the comparison curriculum. In particular, we observed differences in the ways in which Anna and Valerie asked questions, encouraged student participation, and highlighted students' thinking. We elaborate on these differences below.

Anna's general pedagogical approach in teaching with the comparison curriculum involved posing questions, highlighting children's thinking, and encouraging children to participate in class discussions. Anna's routine for implementing the "Understand" phase of the curriculum serves as one illustration. Anna typically began the "Understand” phase by asking for one or more student volunteers to go to the front of the room and "present" one of the methods to be compared. The class seemed to have well-established routines for student participation via 
these presentations, and the children in the class typically enacted them with minimal prompting: the selected volunteer would approach the Smartboard, read aloud (or translate into his or her own words) the dialogue in which the curriculum characters described their solution methods, and point to the mathematical steps that corresponded to each line of dialogue as they read it. As a student volunteer was "presenting” a method, Anna would occasionally interject to pose clarifying questions, check to see if the students in the class understood a particular step, or ask the presenting student to clarify his or her statements.

The following lesson segment is typical of Anna's routine for introducing a comparison activity (see Figure 5). In this segment, she encouraged the participation of a student volunteer in introducing the two strategies to be compared:

Anna: Does anyone want to volunteer to go and read Alex and read Morgan? Go ahead, Andrew. And as usual, please, point to where you are.

Andrew: Alex and Morgan were asked to simplify three squared times three cubed times three squared.

Anna: Okay. Go ahead.

Andrew: First Alex said that he multiplied the exponents [points to the multiplication]. And he got three to the twelfth.

Anna: So how'd he get that twelve?

Andrew: He multiplied two times three times two.

Anna: And that gives you the twelve? Okay, so you can page down to see the rest of Alex’s problem.

Andrew: Then he worked out, he raised three to the power of twelve. And he got [points]. Anna: Okay, can you read that number out loud? 
Andrew: Uh, five hundred thirty-one thousand four hundred forty-one.

Anna: Okay. That's Alex. That's our guy Alex. Go ahead with Morgan.

Andrew: Morgan's product of powers way. She did, she used the product of powers property. And she added the exponents, instead of multiplying [points to the addition of the exponents on the worked example pair]. She did two plus three plus two. And she got three to the seventh power. She did three to the seventh power [points], and she got two thousand one hundred and eighty seven [points].

Anna: Okay. Are both of these kids right?

Students: No.

Andrew: It's this one [points to Morgan's answer].

Anna: How do you know right off the bat that it can't be, they're not both right?

Students: Different answers, 'cause they have different answers.

In this segment, Anna encourages student participation by asking a student volunteer to present the two strategies. She asks clarifying questions, such as by asking how Alex had arrived at a particular value in an intermediary step (“So how'd he get that twelve?"). In these ways, Anna engages the students in previewing the methods to be compared. Note that this routine does not conclude the "Understand" phase in Anna's class. Following this introduction, students would typically work individually or in groups to answer comprehension questions provided in the curriculum materials, then Anna would engage students in a whole-class discussion in which students responded to these "Understand" questions. Anna's pattern of posing questions, highlighting children's thinking, and encouraging children to participate in class discussions continued through the remainder of the Understand phase, and was indeed central to her general pedagogical approach throughout her implementation of the comparison curriculum. 
By contrast, Valerie’s general pedagogical approach was characterized by her tendency to answer questions posed in the curriculum herself, and at times neglecting to interpret students' responses or incorporate them into the discussion. The following illustration is drawn from the same lesson as described above (see Figure 4):

Valerie: Does everybody understand this step, like how he gets from here [points to Alex's second step] to there [points to Alex's third step].

Students: No, no.

Valerie: No? He's saying that if this is an equation, [erases whiteboard] then [rewrites Alex's and Morgan's equations]. All right. So what he's saying is, I don't like fractions. Which I think a lot of people in this class were thinking [nodding] when they saw this, right? So he thought, I want to get rid of this 4 and this 5 . So the best way I can get rid of the 4 and the 5 is if I multiply by 20. [writing] So I'm going to multiply this expression by 20. But if I do that to this side I have to do that to this side. Right? Now let's take a look at what happens when I multiply by 20. If I'm multiplying this side of my equation by 20 [points to left-hand side], I have to do what with that 20 ?

Student: Um. [inaudible] by the $x$ over 4?

Valerie: Distribute it. So when I rewrite this, I can rewrite it as 20 over 1 times $x$ over 4, minus 20 over 1 times $x$ over 5. [writing] Right? If I cancel [writing], I should end up with $5 x$ minus $4 x$, shouldn’t I? Equals negative 40 .

Student: Ohh.

Student: You stumped me. You stumped me.

Valerie: Okay? So that's what he did, in his second step. So his decision was, I don't like these fractions, I'm going to get rid of them. And he's completely able to do that because 
what he did to the left side of the equation he did to the right side of the equation. Right? Kept it balanced. He can do that, right? And once he did that, he has an expression that all of you are very comfortable with evaluating, right? So then you get $5 x$ minus $4 x$ should give you $x . x$ equals negative 40. Done. Right? [nodding] So Morgan sees this and she realizes I can't subtract fractions without a common denominator, she finds a common denominator [pointing], she does that correctly, that step, which a number of people had trouble with, which is worrying me, I have to tell you. [points] Bill, one second. And then when you combine these two expressions, $5 x$ over 20 minus $4 x$ over 20, you get an answer of, this one [pointing], $x$ over 20. $x$ over 20 equals negative 2 is something you should be able to evaluate, isn’t it? You multiply both sides by 20. And you should get an answer of $x$ equals negative 40. Bill.

Bill: When I got the wrong answer, I didn’t look at the subtraction, I looked at it and automatically assumed it was multiplication. So I multiplied, then added. And that's how I got --

Valerie: Okay, but do you see where you went wrong? All right so it's the same rules for an equation, once you have an equation, as long as what you do on the left side is the same as what you did on the right side, you should be able to solve it, all right? So be careful, for those of you who are thinking, oh I have a proportion. Look at the problem carefully before you attack it. And then systematically go through it. So if you look at this, he used his math [gesturing to Alex's way] to make his life easier here. Right? Definitely something you want to consider as you're going through problems. So I'm going to give you a test... 
In this example, the goals of the "Make Connections" phase, in which the teacher was intended to pose to students a series of questions relating to which of the two solutions was better, were alluded to somewhat in Valerie's remarks, but the structured student discussion that was intended to occur in this phase seemed underdeveloped. This lesson segment was typical of Valerie's general pedagogical approach, in that she guided most of the conversation herself, and at times appeared to miss opportunities to encourage or engage with student contributions.

\subsection{Structural Issues}

In addition to the general pedagogical and mathematical differences in the case study teachers' enactments of our curriculum, we also noted some structural differences in Anna's and Valerie’s lesson organization. As noted above, Anna appeared to have developed routines with her students relatively early in the year regarding their participation in the three instructional phases associated with the curriculum, and she consistently implemented all three discussion phases in order. By contrast, Valerie at times skipped one or more of the discussion phases, or skipped back and forth among the discussion phases rather then completing them in order.

\section{Discussion}

The Algebra I teachers in the current study were tasked with enacting a curriculum centered on facilitating mathematically rich (and demanding) discussions centered around the comparison of multiple solution strategies. In the current exploratory pilot study, we sought to explore variations in teachers' implementation of comparison in their Algebra I classrooms, using the lens of two case studies. In exploring these cases, we found that responding to students' mathematical contributions and a focus of discussions meant to help students "make connections” appeared to be key differences between the two focal case study teachers. 
What factors might have contributed to the variability that we observed in the two case study teachers' implementation? While we cannot discern which of the myriad and intertwined factors influencing teachers’ instructional decisions drove the observed instructional outcomes, we speculate that several overlapping factors may potentially have contributed to the observed implementation differences. First, as noted above, at the beginning of the study, one notable difference between these two teachers was in their levels of Mathematical Knowledge for Teaching (MKT). While Anna scored in the $97^{\text {th }}$ percentile on the MKT assessment, a very high score, Valerie scored only scored in the $37^{\text {th }}$ percentile. While it appears plausible that teachers with very high MKT might be more comfortable with, for example, asking open-ended questions and entertaining children's mathematical ideas than teachers with weak MKT, nevertheless teachers' practices surrounding asking questions, encouraging participation, and highlighting students' thinking may be related to other factors, such as differences in their prior training and personal beliefs.

However, we note that the area in which we observed the greatest variation between the highest- and lowest-MKT teachers was in responding to students appropriately. The comparison curriculum materials placed heavy emphasis on the use of discussion, with a particular demand for teachers to engage students in mathematical discussions in which they compared and contrasted multiple approaches and probed the mathematical goals of each comparison. Seen in this light, it appears plausible that teachers with higher levels of MKT might be more confident asking open-ended questions and fielding children's own ideas and questions, even when they veered from a teacher's expected or planned course for the lesson. On the MKT, this corresponded to "knowledge of content and students"; similarly, in the affordance literature, this may be linked to highly effective teachers' skill in capitalizing on students' contributions to 
make mathematical points and driving the lesson toward important mathematical points (Fennema \& Franke, 1992). As Hill et al. (2005) have argued, responding to students appropriately is a mathematically demanding task, since students may articulate their ideas using language, analogies, or examples that are only partially developed or mathematically unclear. In this context, teachers must rapidly make sense of students' sometimes incomplete or unclear expressions, and use them to build toward a coherent and important mathematical point. Especially in the context of a spoken class discussion, where the teacher does not have the luxury of time to decipher students' methods that she might have when analyzing written work, the mathematical demands on a teacher of interpreting students' mathematical utterances in real time may be intense.

In response to these demands, the high- and lower-MKT teachers in the current study employed divergent tactics in their implementation. Anna, whose MKT was very high, guided the comparison conversations so as to draw out and build upon students' mathematical ideas, displayed and responded to students' errors and sometimes inarticulate contributions quickly, and consistently pushed students to justify their conclusions about the relationships between the compared methods using mathematical tools. Valerie, whose MKT was much lower, at times appeared to struggle to respond to students' questions and alternative methods as they came up in the comparison conversation. On the MKT assessment, Valerie scored particularly low on questions that involved interpreting students' mathematical statements and alternative approaches, and identifying and diagnosing the nature of students' errors. In the classroom, Valerie also appeared at times to struggle to interpret her own students’ mathematical thinking.

As a research team, we utilized our examination of the cases of Anna and Valerie in order to inform our subsequent refinement of the professional development and training materials for 
Algebra I teachers new to the practice of comparison in several key ways. First, based on our observation that Valerie and several other pilot teachers were inconsistent in implementing the structural architecture of the 3-phase comparison discussion as envisioned, we revised our professional development materials to provide teachers with clearer messages and practice around the goals and structure of the 3-phased discussion. We created and shared with teachers a more explicit 3-phased Discussion Guide (see Figure 8), and made this guide an important part of professional development discussions and activities. For example, in our refined professional development agenda, teachers designed 'model teaching' lessons (Newton \& Star, 2013) around the 3-phased Discussion Guide, and reflected on how they planned to incorporate each phase in their instructional practice.

Second, based on our observation that Valerie and some other pilot teachers were inconsistent in implementing the Make Connections phase of the 3-phased discussion model, we refined our professional development materials in order to focus teachers' attention more closely on this phase of the comparison discussions. First, we provided teachers with 'takeaway pages' related to each comparison lesson, which aimed to serve as a visual reminder to teachers to culminate their classroom discussions with a summary of the important mathematical points that the discussion had highlighted (see Figure 9 for an example of a 'takeaway' visual). We emphasize that the goal of the 'takeaways' was not as an indication of the only recommended mathematical points germane to the discussion, but rather as a visual reminder and prompt to teachers to provide students with a clear summary of the important mathematical ideas that had emerged via the discussion (Stein, Engle, Smith, \& Hughes, 2008). In addition, we refined the professional development activities to provide teachers more opportunities for discussion of the mathematical goals of each comparison pair, both in small groups and in larger sessions, and to 
reflect on and practice how they would specifically implement the Make Connections phase in their classrooms.

\subsection{Limitations}

This study has multiple limitations. For one, it is observational in nature, meant to explore ideas about two focal teachers' implementation of a new curriculum. We suspect that it is likely that myriad factors, including teachers' MKT but also their prior experiences, ideas and views about their students, and beliefs and attitudes about multiple strategies likely interacted to shape their implementation. As an example, while the current case study teachers were quite similar in some aspects of their background, as we noted above, they taught in somewhat different classroom and school environments. While Anna, the teacher with the very high MKT score, taught in a diverse, urban school that served many students from low-income families, Valerie, whose MKT score was substantially lower, taught honors eighth grade Algebra I in a predominantly middle-class suburb. As we noted above, Valerie's students outscored Anna's students by about 20 percentage points on a standardized algebra readiness pretest administered at the beginning of the project year. Anna’s and Valerie’s different student populations may have contributed to differences in their implementation. However, we note that the direction of this relationship is not obvious, since Anna, whose students were much weaker in prerequisite algebra skills at baseline, nonetheless appeared to attempt mathematically demanding discussions with her students to a more consistent degree than did Valerie.

In addition (and perhaps relatedly), teachers in the current pilot study were given substantial flexibility in selecting which curriculum materials to utilize with their students. In turn, Anna and Valerie did not teach any of the same lessons on the days in which they were videotaped. As a result, we were unable to make direct comparisons between Anna and Valerie 
teaching the same lesson. It seems plausible that this flexibility in materials selection may have meant that Anna may have selected lessons covering relatively less complex content than did Valerie; if so, perhaps Valerie's task in leading comparison discussions may have been relatively more difficult. In future studies, it would be useful for researchers to examine teachers from diverse backgrounds teaching identical comparison lessons, in order to probe potential implementation differences within a single lesson.

In addition, in the current study we have analyzed the cases of only the teachers with high and relatively low to average MKT; in the future, it would be interesting to compare and contrast the implementation of teachers reflecting a diverse range of MKT. In such a study, it would also be interesting to consider multiple teachers whose MKT was very similar, in order to probe further into areas of teachers' implementation where important differences persisted. Future research should also examine the impact of comparison curricula on students' test scores, in order to explore whether this approach may benefit student achievement outcomes.

\section{Conclusions}

The current study explored differences in the implementation of a comparison-focused Algebra I curriculum between two case study teachers. Our task in this analysis differed from measuring teachers' mathematical quality of instruction generally (e.g. Hill et al., 2008), in that the curriculum under consideration was developed to embed multiple qualities associated with high mathematical quality of instruction on other measures (such as Hill et al.'s MQI) in its design. Specifically, while Hill and colleagues found that characteristics of high MQI included exposing students to multiple strategies, linking among representations, and utilizing cognitively demanding tasks, the current curriculum materials were designed explicitly to embody these 
qualities. The resulting curriculum in turn includes some challenging pedagogies, particularly engaging students in the comparison and discussion of multiple strategies.

What did instruction incorporating the comparison of multiple strategies look like in these two classrooms? On the one hand, for Valerie, incorporating the curriculum materials into her instruction did appear to elevate the mathematical level of the materials to which her students were exposed. While much of the rest of Valerie's instruction (not detailed here) largely followed the archetypal trajectory of an American math lesson, from demonstration of a procedure to structured and then independent practice, the comparison portions of her lessons did expose students to multiple solutions and to questions that challenged them to make connections. However, as illustrated above, Valerie did appear to miss some opportunities to engage students in a nuanced mathematical comparison of multiple approaches. In the hands of Anna, these same curriculum materials served as a springboard for relatively rich (albeit imperfect) mathematical discussions in which her population of struggling algebra students participated actively in debates about the relative efficiency of multiple methods and justifications of why various methods worked.

This study paints a preliminary and exploratory picture of how Algebra I teachers implemented comparison-focused curriculum materials with challenging pedagogies characteristic of high mathematical quality of instruction embedded in their design. The differences in the curriculum implementation that we observed suggested to us key extensions of the pedagogical and training supports that we provided to teachers, specifically tailored to guide teachers' facilitation of the three-phased comparison discussion, could have the potential to strengthen and enrich teachers' implementation of algebraic comparisons. Further research in this area should continue to iteratively refine and test these pedagogical strategies for supporting 
comparison among early algebra learners, in order to meet the goals for comparison and understanding of multiple approaches put forth in curriculum policy documents. 


\section{References}

Borko, H., Mayfield, V., Marion, S., Flexer, R., \& Cumbo, K. (1997). Teachers' developing ideas and practices about mathematics performance assessment: Successes, stumbling blocks, and implications for professional development. Teaching and Teacher Education. 13(3), 259-278. doi: 10.1016/S0742-051X(96)00024-8

Coburn, C. E. (2005). The role of nonsystem actors in the relationship between policy and practice: The case of reading instruction in California. Educational Evaluation and Policy Analysis, 27, 23-52. doi: 10.3102/01623737027001023

Cohen, D. K., \& Hill, H. C. (2000). Instructional policy and classroom performance: The mathematics reform in California. Teachers College Record, 102(2), 294-343. doi: $10.1111 / 0161-4681.00057$

Cohen, D. K., \& Hill, H. C. (2001). Learning policy: When state education reform works. New Haven, CT: Yale University Press.

Fennema, E., T. P. Carpenter, M. L. Franke, L. Levi, V. Jacobs, and S. Empson. 1996. Learning to use children's thinking in mathematics instruction: A longitudinal study. Journal for Research in Mathematics Education 27 (4): 403-434.

Fennema, E., \& Franke, M. L. (1992). Teachers’ knowledge and its impact. In D. A. Grouws (Ed.), Handbook of research on mathematics teaching and learning: A project of the National Council of Teachers of Mathematics. (pp. 147-164). New York: Macmillan.

Hiebert, J., Gallimore, R., Garnier, H., Givven, K. B., Hollingsworth, H., Jacobs, J., et al. (2003). Understanding and improving mathematics teaching: Highlights from the TIMSS 1999 Video Study. Phi Delta Kappan, 84, 768-775. 
Hill, H. C., Blunk, M., Charalambous, C., Lewis, J., Phelps, J., Sleep, L., et al. (2008). Mathematical knowledge for teaching and mathematical quality of instruction: An exploratory study. Cognition and Instruction, 26, 430-511.

Hill, H. C., Ball, D. L., Blunk, M., Goffney, I. M., \& Rowan, B. (2007). Validating the ecological assumption: The relationship of measure scores to classroom teaching and student learning. Measurement, 5(2-3), 107-118. doi: 10.1080/15366360701487138

Hill, H. C., Dean, C., \& Goffney, I. M. (2007). Assessing elemental and structural validity: Data from teachers, non-teachers, and mathematicians. Measurement, 5(2-3), 81-92.

Hill, H. C., Rowan, B., \& Ball, D. L. (2005). Effects of teachers' mathematical knowledge for teaching on student achievement. American Educational Research Journal, 42, 371-406.

Hill, H. C., Schilling, S. G., \& Ball, D. L. (2004). Developing measures of teachers' mathematics knowledge for teaching. The Elementary School Journal, 105(1), 11-30.

Kilpatrick, J., Swafford, J. O., \& Findell, B. (2001). Adding it up: Helping children learn mathematics. Washington DC: National Academy Press.

Lampert, M. (2001). Teaching problems and the problems in teaching. New Haven, CT: Yale University Press.

Lloyd, G. M., \& Wilson, M. (1998). Supporting innovation: The impact of a teacher's conceptions of functions on his implementation of a reform curriculum. Journal for Research in Mathematics Education, 248-274.

Lynch, K., \& Star, J. R. (in press). Teachers’ views about multiple strategies in middle and high school mathematics. Mathematical Thinking and Learning.

Moses, R. P., \& Cobb, C. E. (2001). Radical equations: Math literacy and civil rights. Boston: Beacon Press. 
National Governors Association Center for Best Practices \& Council of Chief State School Officers. (2010). Common Core State Standards for Mathematics. Washington, DC: Authors.

Newton, K. J., \& Star, J. R. (2013). Exploring the nature and impact of model teaching with worked example pairs. Mathematics Teacher Educator, 2(1), 86-102.

Philipp, R. A. (2007). Mathematics teachers' beliefs and affect. In F. Lester (Ed.), Second handbook of research on mathematics teaching and learning. Reston, VA: National Council of Teachers of Mathematics.

Putnam, R. T., Heaton, R., Prawat, R. S., \& Remillard, J. (1992). Teaching mathematics for understanding: Discussing case studies of four fifth-grade teachers. Elementary School Journal, 93(2), 213-228.

Rittle-Johnson, B. \& Star, J.R. (2009). Compared with what? The effects of different comparisons on conceptual knowledge and procedural flexibility for equation solving. Journal of Educational Psychology, 101(3), 529-544.

Rittle-Johnson, B., \& Star, J. R. (2007). Does comparing solution methods facilitate conceptual and procedural knowledge? An experimental study on learning to solve equations. Journal of Educational Psychology, 99(3), 561-574.

Rittle-Johnson, B., Star, J. R., \& Durkin, K. (2009). The importance of prior knowledge when comparing examples: Influences on conceptual and procedural knowledge of equation solving. Journal of Educational Psychology, 101(4), 836-852.

Rittle-Johnson, B., \& Star, J. R. (2011). The power of comparison in learning and instruction: Learning outcomes supported by different types of comparisons. In J. P. Mestre \& B. H. 
Ross (Eds.), Psychology of Learning and Motivation: Cognition in Education (Vol. 55, pp. 199-222). Waltham, MA: Elsevier. doi:10.1016/B978-0-12-387691-1.00007-7

Silver, E. A., Ghousseini, H., Gosen, D., Charalambous, C., \& Strawhum, B. (2005). Moving from rhetoric to praxis: Issues faced by teachers in having students consider multiple solutions for problems in the mathematics classroom. Journal of Mathematical Behavior, 24, 287-301.

Stein, M. K., Baxter, J. A., \& Leinhardt, G. (1990). Subject-matter knowledge and elementary instruction: A case from functions and graphing. American Educational Research Journal, 27(4), 639-663.

Stein, M. K., Engle, R. A., Smith, M. S., \& Hughes, E. K. (2008). Orchestrating productive mathematical discussions: Five practices for helping teachers move beyond show and tell. Mathematical Thinking and Learning, 10(4), 313-340.

Stein, M. K., Kaufman, J. H., Sherman, M., \& Hillen, A. F. (2011). Algebra: A challenge at the crossroads of policy and practice. Review of Educational Research, 81I, 453-492. doi: $10.3102 / 0034654311423025$

Woodward, J., Beckmann, S., Driscoll, M., Franke, M., Herzig, P., Jitendra, A., Koedinger, K. R., \& Ogbuehi, P. (2012). Improving mathematical problem solving in grades 4 through 8: A practice guide (NCEE 2012-4055). Washington, DC: National Center for Education Evaluation and Regional Assistance, Institute of Education Sciences, U.S. Department of $\begin{array}{llll}\text { Education. } & \text { Retrieved http:// }\end{array}$ ies.ed.gov/ncee/wwc/publications_reviews.aspx\#pubsearch/. 
Figure 1. Example of released specialized content knowledge item from an earlier version of the Mathematical Knowledge for Teaching elementary level assessment (Hill, Schilling, \& Ball, 2004).

At a professional development workshop, teachers were learning about different ways to represent multiplication of fractions problems. The leader also helped them to become aware of examples that do not represent multiplication of fractions appropriately.

Which model below cannot be used to show that $1 \frac{112}{2}$ 2/3=1? (Mark ONE answer.)

A)

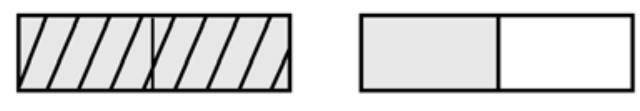

B)
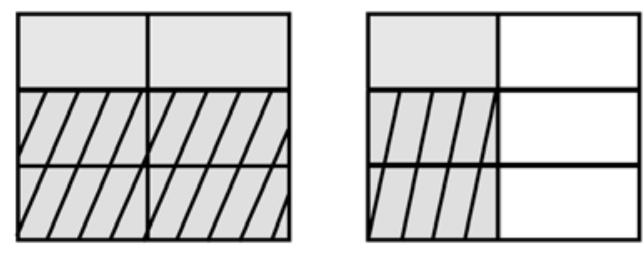

C)
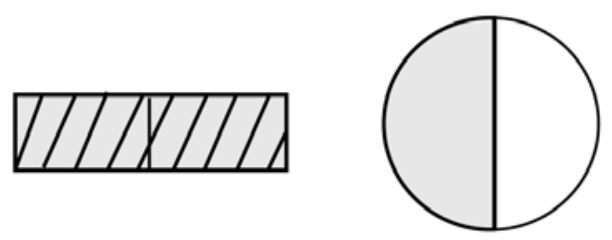

D)

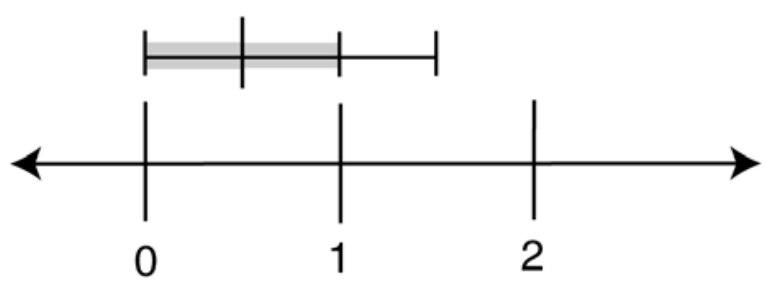


Figure 2. Example of released knowledge of content and students (KCS) item from an earlier version of the Mathematical Knowledge for Teaching elementary level assessment (Hill, Schilling, \& Ball, 2004).

Students in Mr. Hayes' class have been working on putting decimals in order. Three students — Andy, Clara, and Keisha — presented 1.1, 12, 48, 102, 31.3, .676 as decimals ordered from least to greatest. What error are these students making? (Mark ONE answer.)

a) They are ignoring place value.

b) They are ignoring the decimal point.

c) They are guessing.

d) They have forgotten their numbers between 0 and 1 .

e) They are making all of the above errors. 
Figure 3. Example of comparison curriculum materials featuring the characters Alex and

Morgan.

Which is Correct?

Alex and Morgan were asked to solve $45 y+90=60 y$

Alex's "combine like terms" way

Morgan's "combine like terms" way
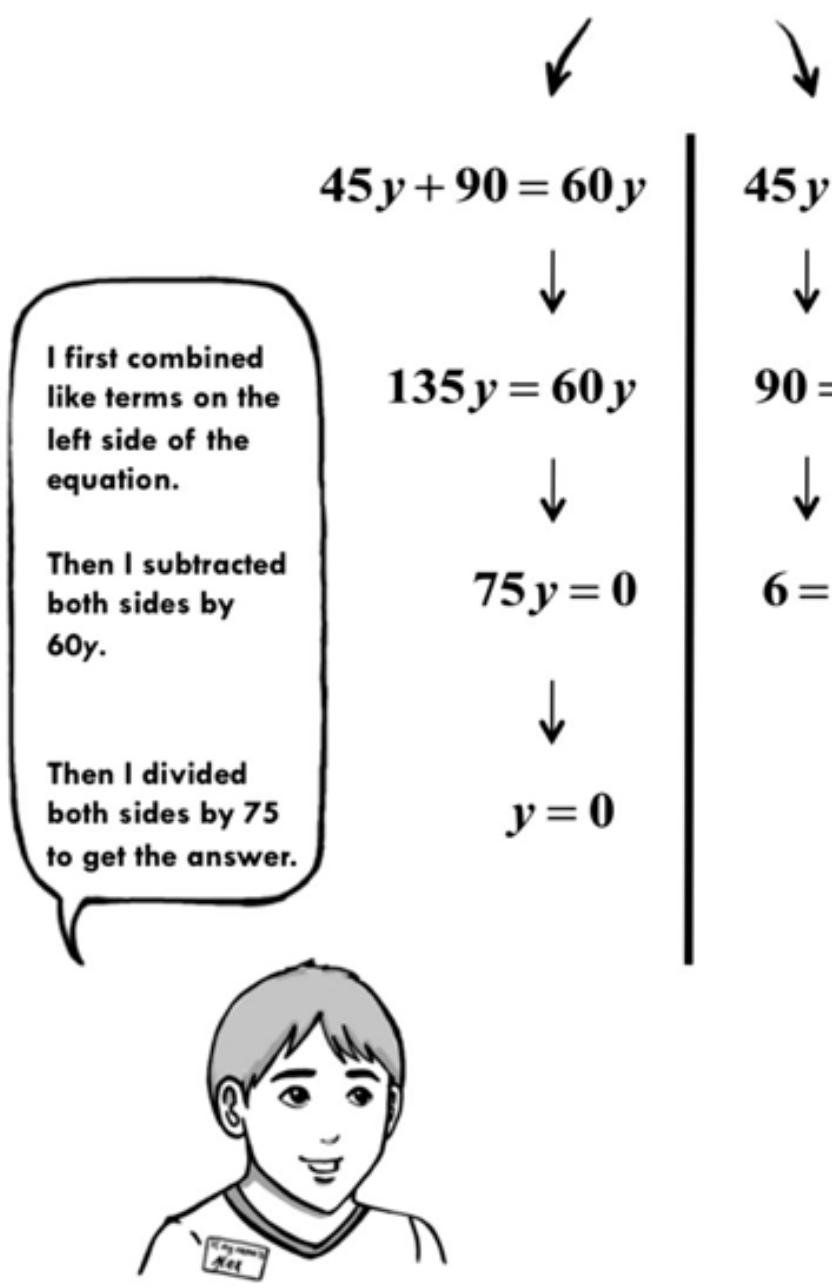

$45 y+90=60 y$

$=60 y$

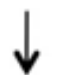

I first combined like ferms on the

left side of the

Then I subtracted

both sides by

$60 y$.

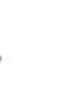

$35 y=60 y$

$\downarrow$

$75 y=0$

$6=y$

First I subtracted

$45 y$ on either side; $60 y-45 y$ is $15 y$.

Then I divided both sides by 15 to get the answer.

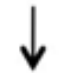

$$
\boldsymbol{y}=\mathbf{0}
$$

* How did Alex solve the equation?

* How did Morgan solve the equation?

* Why did Alex combine the terms on the left as a first step?

* Why did Morgan subtract $45 y$ as a first step?

* Which way is correct, Alex's or Morgan's way? How do you know?

* Can you state a general rule about combining like terms that describes what you have learned from comparing Alex's and Morgan's ways of solving this type of problem? 
Figure 4. Example of curriculum materials from Valerie's lesson.

Which is better?

Alex and Morgan were asked to solve $\frac{x}{4}-\frac{x}{5}=-2$

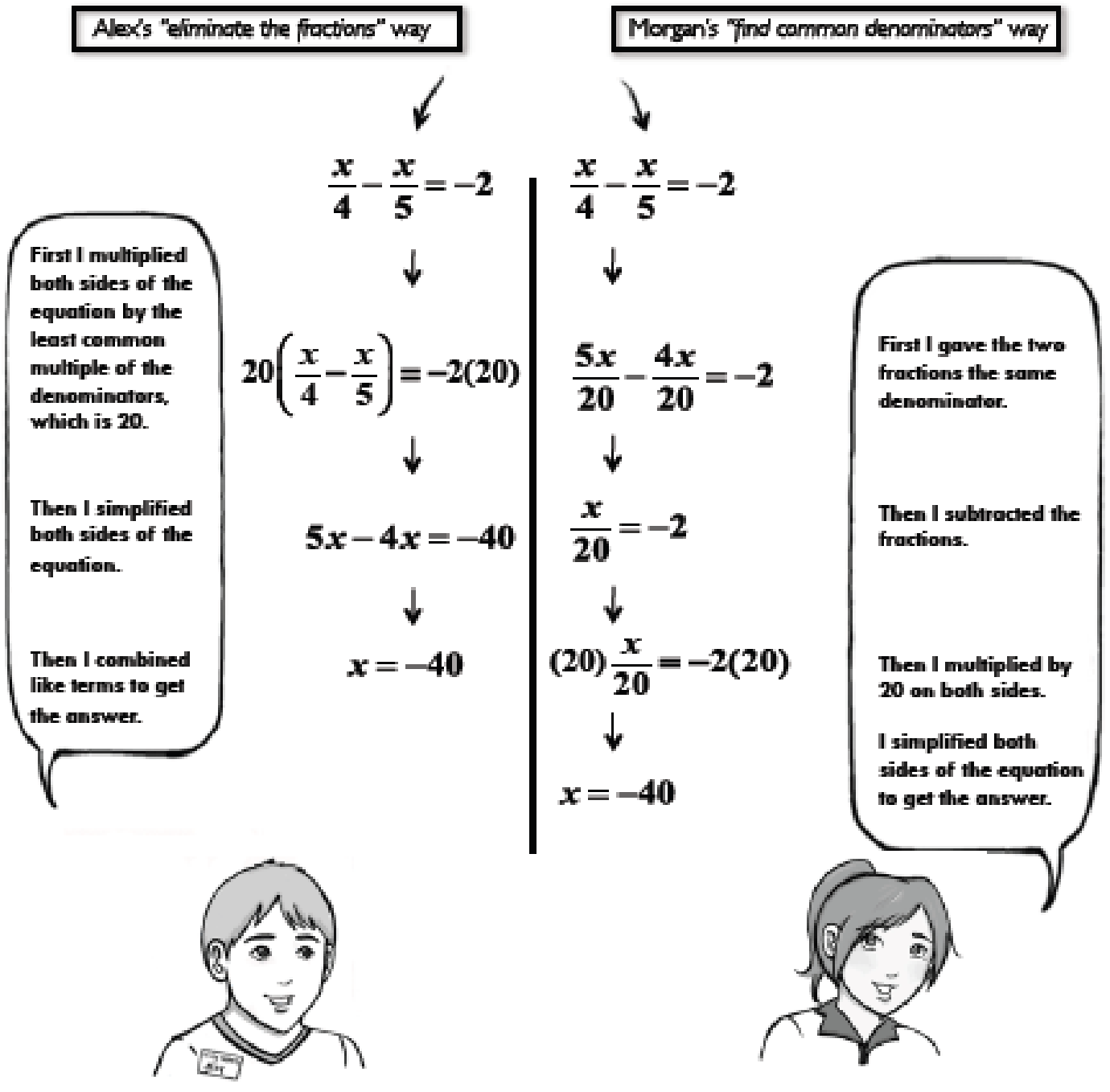

+Why did Alex mulfiply each term by 20 as a first step?

- Why did Morgan find a common denominator as a first step?

- What are some similarities and differences between Alex's and Morgan's ways?

-Which way is easier, Alex's way or Morgan's way? Why? 
Figure 5. Example of curriculum materials from Anna’s lesson.

Which is correct?

Alex and Morgan were asked to simplify $3^{2} \cdot 3^{3} \cdot 3^{2}$

Alex's "multiply the exponents" way

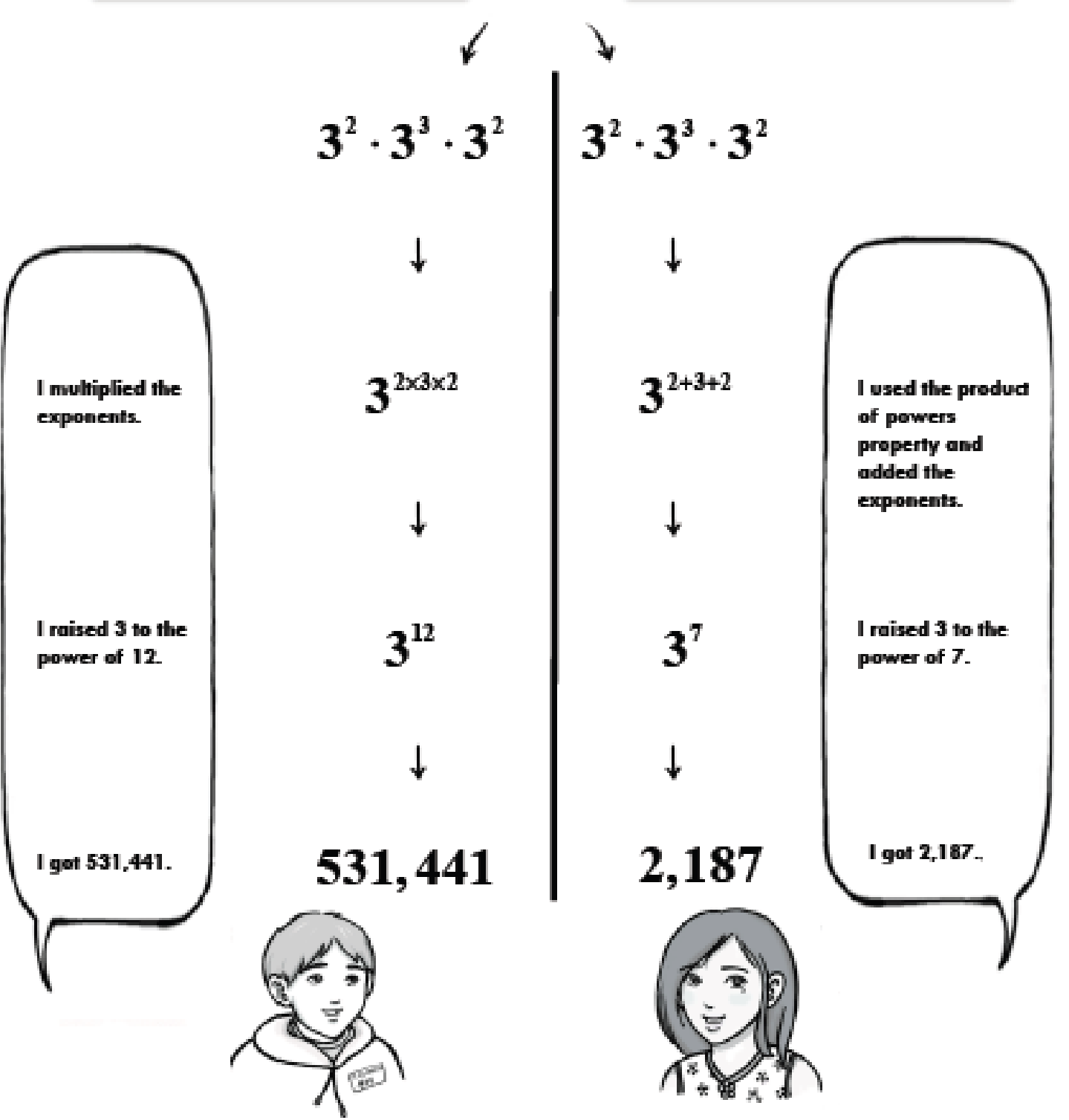

+ How did Alex simplify the expression?

- How did Morgan simplify the expression?

- Which answer is correct, Alex's or Morgan's? How do you know?

-What are some similarities and differences between Alex's and Morgan's ways?

+What if the problem were changed to $x^{2}-x^{3}-x^{2}$ ? What would the answer be? 
Figure 6. Example of curriculum materials from Anna’s lesson.

Why does it work?

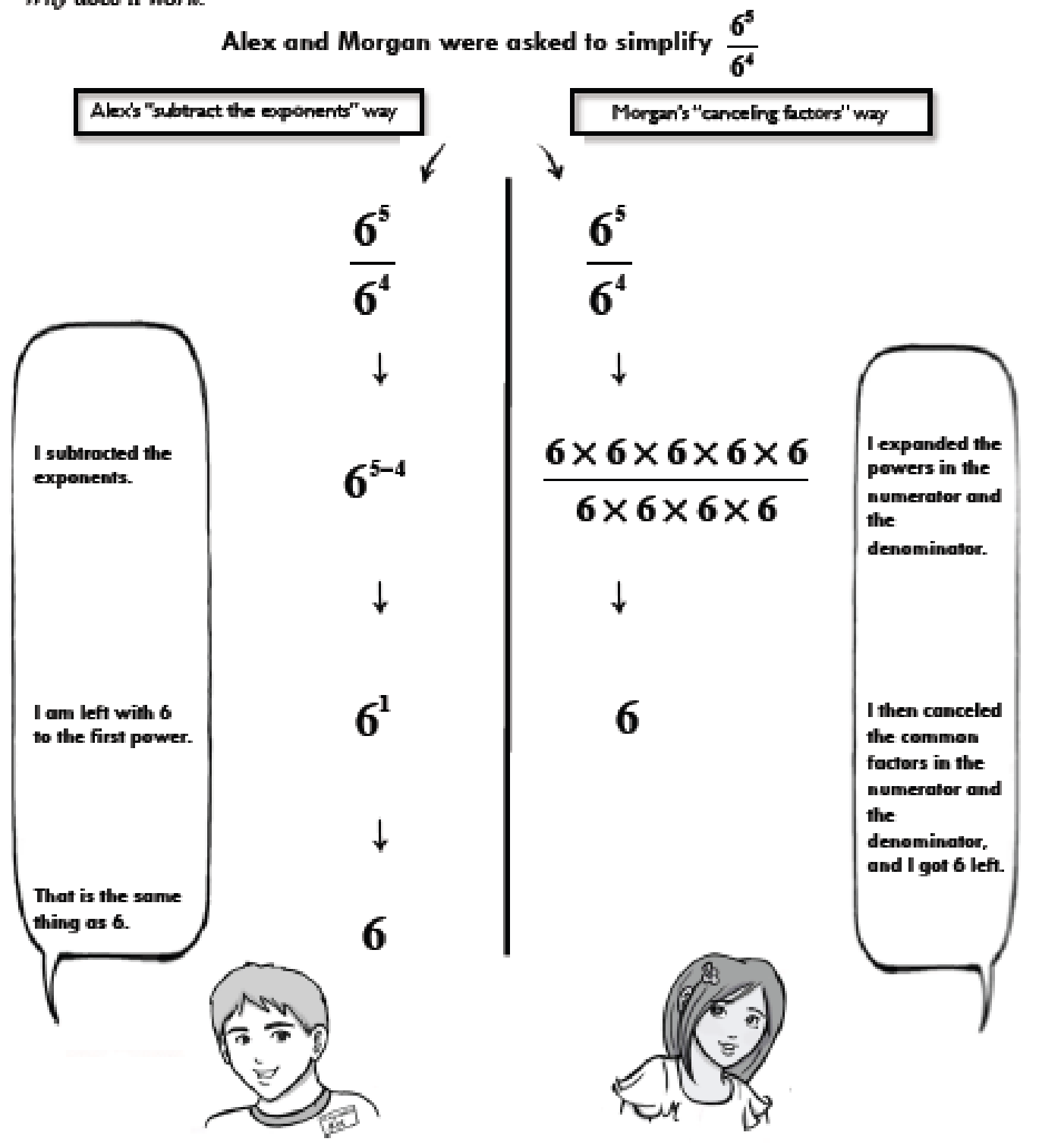

- How did Alex simplify the expression?

* How did Morgan simplify the expression?

- What are some similarities and differences between Alex's and Morgan's ways?

- Does Alex's way always work? $\frac{6^{2 s}}{6^{n}}$ 
Figure 7. Example of curriculum materials from Valerie’s lesson.

How do they differ?

Alex and Morgan were given the set of ordered pairs $\{(-3,6),(2,5),(3,1),(2,4)\}$, and asked to determine if the relation is a function.

Alex's "make a table of values" way

Morgan's "graph and use the vertical line test" way
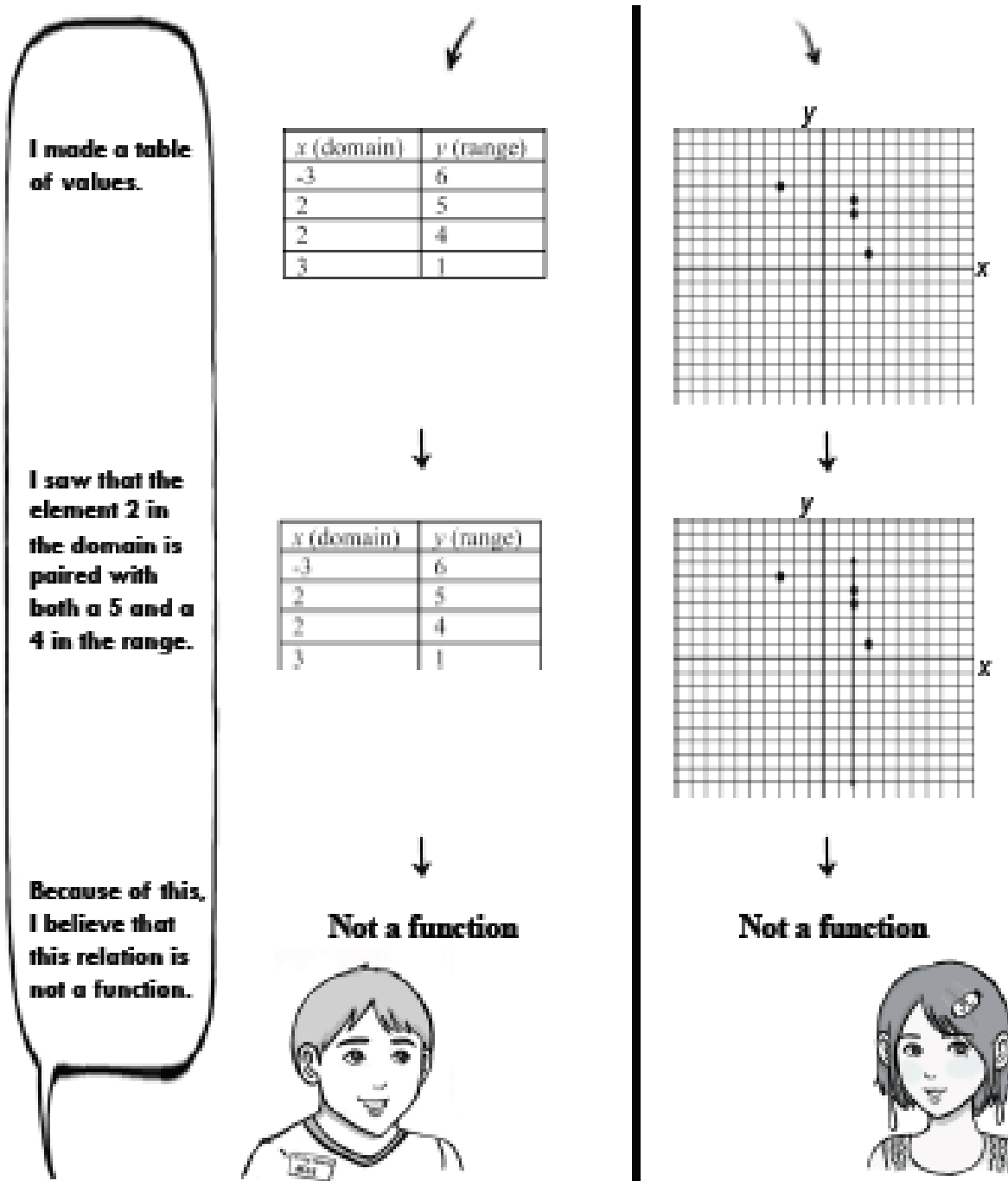

Then I tried

using the

vertical line

test. I found

that I could

draw a vertical

line that

intersected my

graphed points

more than

once.

$\downarrow$

Not a function

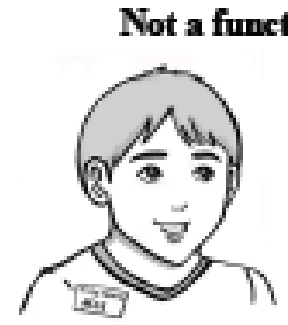

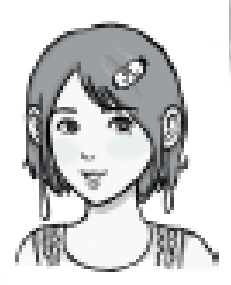

Because of this,

I believe that

this relation is

not a function.

- How did Alex complete the problem?

- How did Morgan complete the problem?

- Describe a way in which Alex's and Morgan's ways are similar.

+ Describe a way in which Alex's and Morgan's ways are different.

- Why does the vertical line test fell us the same thing as the fable of values?

+ Can you think of another way of determining whether this relation is a function, besides Alex's way and Morgan's way?

- If the problem were changed so you were instead asked to determine whether $y=2 x+6$ was a function, would you use Alex's way or Morgan's way? Why? 
Figure 8. Examples of questions typical of the three comparison discussion phases.

\section{DISCUSSION PHASES}

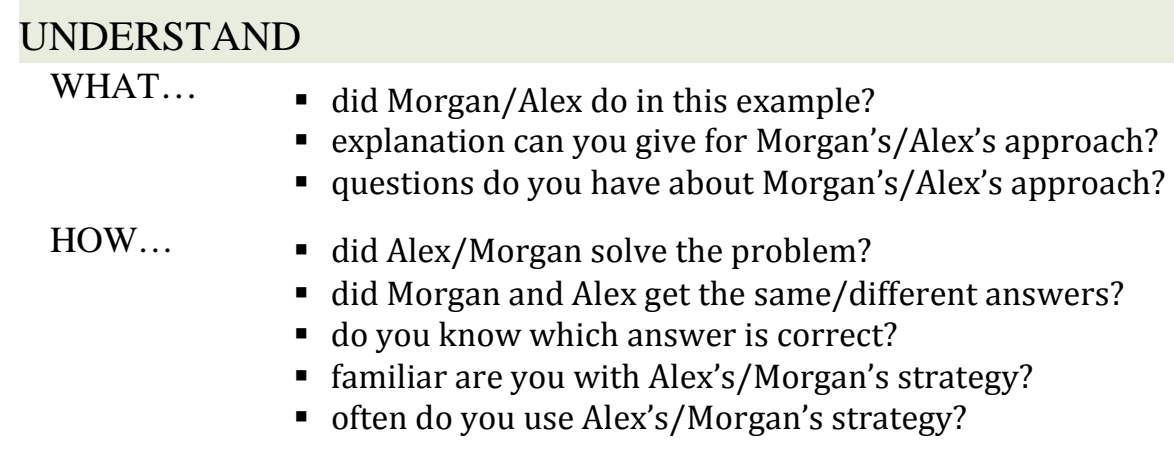

\section{COMPARE}

WHAT...

- are the similarities and differences between Morgan's and Alex's ways?

- can you say about these similarities and differences?

- approach would you suggest your classmate use when she/he has to solve a similar problem?
HOW... - similar or different are these two strategies?
- would you justify Alex's/Morgan's strategy?
WHICH
STRATEGY... - produces a correct/incorrect answer?
- is more efficient?
- is faster to complete?
- is less prone to errors?
- is more accurate?
- $\quad$ would you use on a timed test?

- significant are the differences between Alex's and Morgan's strategies?

- would you explain the differences in the answers?

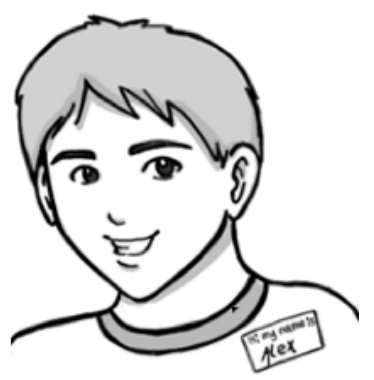

\footnotetext{
MAKE CONNECTIONS

WHY...

- did Alex and Morgan get the same/different answers?

- did Alex's method produce a correct answer and Morgan's did not (or vice versa)?

- is Morgan's/Alex's way more efficient?

- is Morgan's/Alex's way more accurate?

- can we use both of these methods to solve this problem?

WHEN... - - does it makes sense to use/not use Alex's/ Morgan's strategy and why?

- does the difference between using one or the other strategy matter?

- can you use both of these methods to solve a problem?

- does Alex's/Morgan's strategy work/not work?

- is Alex's/Morgan's strategy better, and why?
} 
Figure 9. Example of discussion takeaway page as a visual prompt.

How do they differ?

Alex was asked to simplify $6 \div 2$, and Morgan was asked to simplify $6 \cdot \frac{1}{2}$

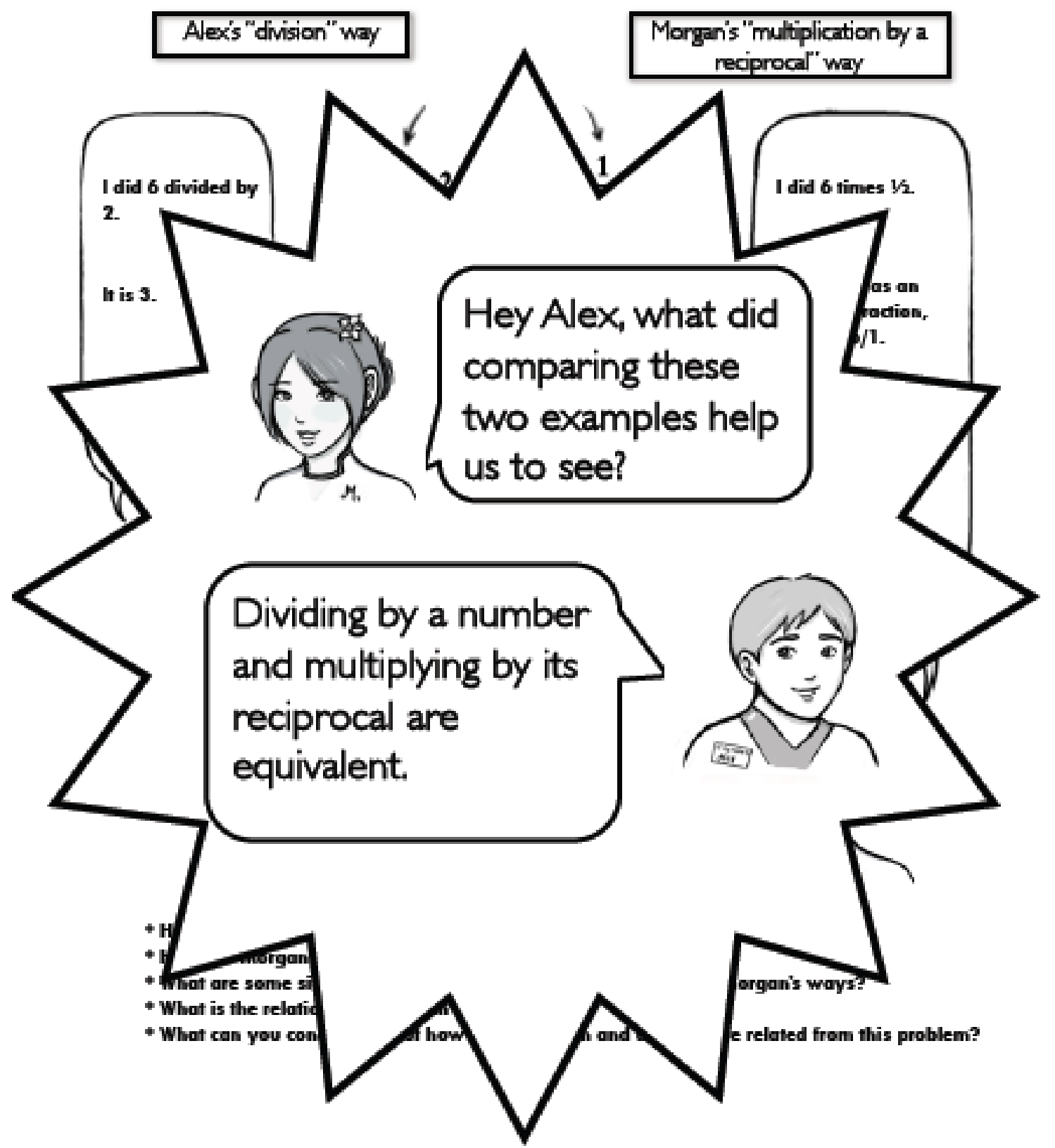

2.2.1 